\title{
Produzindo histórias não lineares: um incentivo à produção escrita e leitura, através do uso contextualizado da tecnologia
}

\author{
Elaine Silva Rocha Sobreira1, Maria Cristina Nunes², Sandra Benedita Morassi ${ }^{3}$ \\ 1,2 e EMEB José Cataldi - PMSBC \\ São Bernardo do Campo, São Paulo - Brasil. \\ elainesilvarocha@gmail.com, mcristina.nunes@ig.com.br, profsandra_@hotmail.com
}

\begin{abstract}
This meta-paper describes the work developed with students of a public school, based on the goal of the curriculum of the first quarter, which intended, among other things, stimulate a quality writing production. For this, was made use of technological resources that would make possible the construction of a non-linear story, resignifying the capability of reconstruction of narratives, with new hypotheses for develop the storyline and favoring of the a relative interactivity given to reader, which in turn, may choose to follow different pathways throughout history. In this work, the technology showed up as a strong ally in the integration of its resources in order to achieve the educational purposes in a pleasurable and creative way.
\end{abstract}

Resumo. Este meta-artigo descreve o trabalho desenvolvido com alunos de uma escola pública municipal, partindo do objetivo do currículo do primeiro trimestre que pretendia estimular uma produção escrita de qualidade. Para isto, foi feito uso de recursos tecnológicos que tornassem viável a construção de uma história não linear ressignificando a capacidade de reconstrução de narrativas, com novas hipóteses de desenrolar do enredo e o favorecimento de uma relativa interatividade dada ao leitor que, por sua vez, pode optar por seguir diferentes caminhos no decorrer da história. Neste trabalho, a tecnologia mostrou-se como uma forte aliada na integração de seus recursos para o alcance dos objetivos educacionais de forma prazerosa e criativa.

\section{Introdução}

Produzir narrativas no ensino fundamental é um conteúdo que permeia todo o currículo, sempre proposto com uma intencionalidade pedagógica de melhoria da escrita dos nossos aprendizes e estímulo à prática de leitura. Neste trabalho, o desafio era tornar a escrita mais prazerosa e significativa, com potenciais leitores que tivessem o prazer de ler esta produção de uma forma mais dinâmica, com uma relativa "interatividade", ou seja, em que o leitor pudesse também ter uma atuação, tornando a produção atrativa. Partindo desta premissa, optamos pelo trabalho com histórias não lineares. Nestas histórias, o autor cria mais de uma linha narrativa e dá oportunidade ao próprio leitor de optar por possíveis desdobramentos da história, pré-estabelecidos pelo autor. Assim, o leitor consegue, de certa forma, modelar a narrativa que está lendo e permitir que a cada nova leitura seja criada uma nova história com desfechos diversificados. Trata-se de uma maneira de atrair os leitores infantis e favorecer as possibilidades de tomadas de decisão, a realização de uma leitura não linear própria dos leitores internautas, aliados 
ao uso da tecnologia. Para os autores, esta criação desenvolve a arte de contar e reconstruir histórias que poderiam ter sido dadas como acabadas.

Este estudo descreve o trabalho desenvolvido na EMEB José Cataldi, escola pública municipal de São Bernardo do Campo (PMSBC), que teve como ponto de partida o objetivo do currículo do primeiro trimestre que pretendia, dentre outros, estimular uma produção escrita de qualidade com contos maravilhosos. Verificada a dificuldade dos educandos em construírem uma boa narrativa, com contextualização, aprofundamento nos fatos e riqueza de detalhes, a atenção voltou-se para uma sistematização do trabalho, por meio de uma proposta que fizesse sentido a escrita de um bom texto, com uma finalidade interessante tanto para os produtores, quanto para os leitores finais. Nada melhor do que aliar a tecnologia neste contexto e criar uma história não linear, em que os alunos pudessem percorrer por links e tomar decisões por quais caminhos seguir, lembrando os percursos que realizam ao navegar na internet, já que os nativos digitais estão habituados, conforme descreve Prensky (2010), a um "aprendizado livre", "não forçado", pois ao navegarem na internet, gostam de multitarefas, preferem leituras de imagens e seguem uma inconstância propiciada pelos hipertextos, reunindo informações que eles colhem de maneira aleatória. A apreciação pelas tecnologias também é afirmada por Valente (2008), o qual ressalta que as crianças são contemporâneas destas tecnologias, elas cresceram junto com elas.

\section{Metodologia e recursos utilizados}

A metodologia adotada baseou-se em uma pesquisa com abordagem empírica e qualitativa a qual trata do desenvolvimento de uma "pesquisa-ação" que consistiu em um trabalho a partir da prática pedagógica docente aplicada em duas turmas do $5^{\circ}$ ano do ensino fundamental I da EMEB José Cataldi - PMSBC, totalizando 54 discentes. Esta unidade escolar conta com laptops educacionais e laboratório de informática, tendo ambos, acesso à internet.

O trabalho pedagógico se desenvolveu no primeiro trimestre de 2013 e contou com o auxílio dos recursos das TIC's, procurando vivenciar o uso de recursos tecnológicos para a melhoria da produção escrita e o oferecimento de uma leitura mais dinâmica. Foram utilizados recursos tecnológicos disponíveis nos laptops educacionais que, por sua vez, propiciam a utilização de um computador por aluno e favorecem o processo de pesquisa e revisão textual. Além disso, este trabalho contou também com os recursos do laboratório de informática, sendo um computador para cada dupla, com a possibilidade de utilização de programas de edição de imagem (Gimp 2 e Tux Paint) em uma tela de tamanho mais acessível e maior resolução e com atividade de criação colaborativa e com o uso do projetor multimídia nas tomadas de decisões coletivas. 


\section{Objetivos do trabalho desenvolvido em sala de aula com auxílio dos recursos tecnológicos:}

Os objetivos do trabalho almejavam que ao final do processo os alunos fossem capazes de:

$\checkmark$ Ler e interpretar textos com autonomia, construindo critérios para seleção de leituras;

$\checkmark$ Reescrever textos coerentes a partir de leituras realizadas;

$\checkmark$ Produzir textos de autoria coesos e coerentes, seguindo características do gênero previsto;

$\checkmark$ Utilizar a ortografia, gramática e pontuação adequadas;

$\checkmark$ Reconstruir o enredo criado, dando origem a novas versões;

$\checkmark$ Utilizar programas livres de edição de imagens para criação de ilustrações digitais;

$\checkmark$ Utilizar a tecnologia para tornar a leitura dinâmica e atraente.

O trabalho foi desenvolvido pautado nos objetivos citados. No decorrer do processo, converteu-se em uma importante fonte de pesquisa, por buscar formas diferenciadas de valorizar a produção escrita do aluno, através do auxílio dos recursos computacionais que muito tem a oferecer para o desenvolvimento de novas formas de leitura e escrita mais interativa e, consequentemente, atraente tanto para os produtores, quanto para os leitores, além de trabalhar com diferentes habilidades e recursos.

\section{Desenvolvimento do trabalho}

Em sala de aula, o trabalho foi iniciado com o estudo das obras "As mil e uma noites" e "Sherazade" para contextualizar a origem do tema "Contos Maravilhosos". Em seguida, foram realizadas diferentes versões de leituras da mesma história de autores variados, utilizando recursos diversos como livros, vídeos e áudios (a bibliografia utilizada como estudo em sala de aula está disponível no final deste artigo).

Realizaram-se pesquisas dos aspectos culturais presentes nos locais onde se desenvolvem o enredo destes contos, por meio do uso dos laptops educacionais. A partir desta, foram construídos cartazes juntamente com a turma, coletando os dados prévios e levantamentos de todos os contos lidos para expor na sala de aula, com o objetivo de identificar os seguintes aspectos textuais: 
$\checkmark$ Origem dos contos maravilhosos;

$\checkmark$ Local onde se desenvolve o enredo;

$\checkmark$ Temática envolvida;

$\checkmark$ Características marcantes dos personagens protagonistas e antagonistas

$\checkmark$ Presença de recursos mágicos

$\checkmark$ Situações comuns nas diferentes histórias

$\checkmark$ Levantamento de nomes pessoais próprios do contexto

Parte deste levantamento é possível ser visualizado na imagem a seguir:

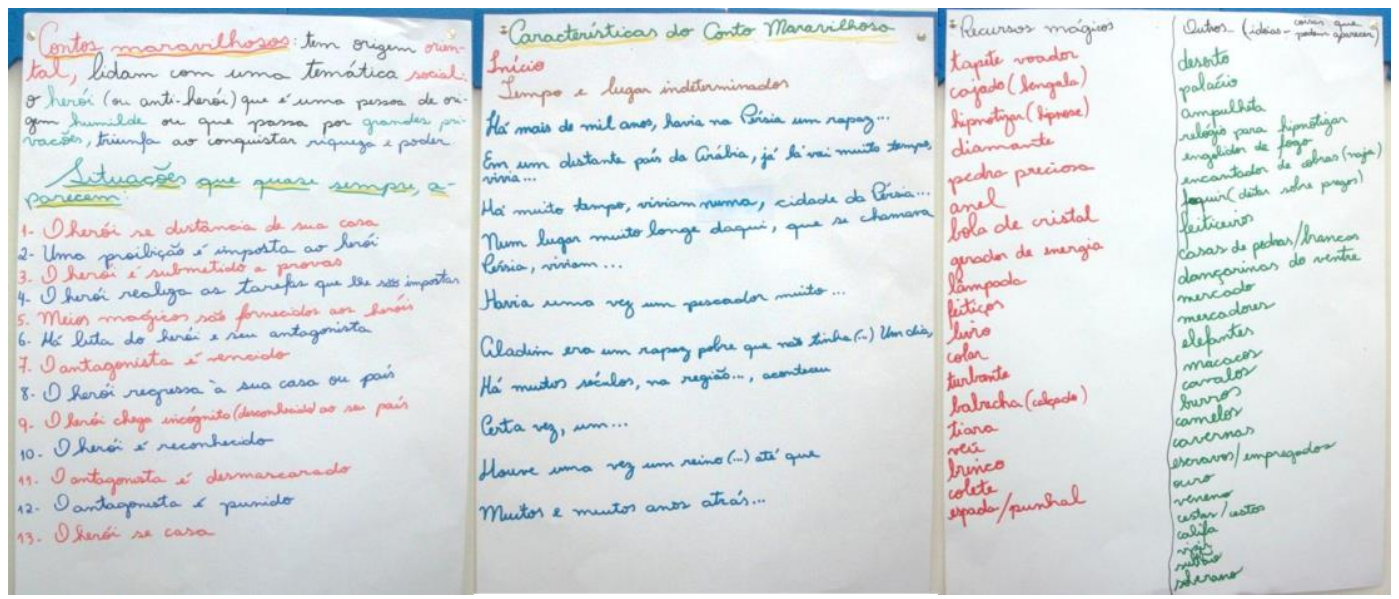

Figura 1 - Alguns dos cartazes criados para identificação dos aspectos característicos do gênero "contos maravilhosos"

Seguindo este roteiro, os alunos reescreveram histórias contadas como "Sherazade" e "Aladim e a lâmpada maravilhosa", com o auxílio dos laptops educacionais, os quais proporcionaram uma escrita minuciosa e revisada, com o auxílio do revisor de texto. De acordo com Miranda et. all, 2011, os alunos passam mais tempo trabalhando nos seus textos quando usam processadores de textos no computador, além da possibilidade destes textos ficarem mais claros.

Em seguida, produziram um conto maravilhoso coletivo, orientados pela professora da turma, e participaram com suas opiniões que obedeciam as características pertinentes ao tema, tendo a oportunidade de praticar o aperfeiçoamento da capacidade de revisão textual e melhoria colaborativa da escrita.

Com o texto finalizado, as professoras verificaram o bom resultado obtido e perceberam que poderiam ir além, produzindo algo de interesse aos demais alunos desta 
instituição para que estes pudessem ter contato com o trabalho realizado, valorizando assim, a produção dos demais alunos.

Neste contexto, no laboratório de informática foram apresentados exemplos de histórias não lineares, que muito chamou a atenção destes, sendo proposta a produção de uma história não linear com o texto criado pela turma. De acordo com Velloso e Marinho (2011), um importante papel da escola é o de "propiciar descobertas para novos usos pedagógicos da tecnologia" cabendo, à escola, o desafio de "incorporar essas tecnologias possibilitando a interação, a participação e a coautoria no processo de ensino e aprendizagem". Prontamente os alunos aceitaram o desafio de criar uma nova narrativa para a história, tornando-a mais atrativa com os recursos tecnológicos.

Foi realizada uma atenta leitura para identificação de momentos no enredo, em que era possível tomar decisões diferenciadas para criar novas versões e caminhos por onde a história poderia seguir, desta forma, os alunos decidiam que outros acontecimentos poderiam ser interessantes para modificar os rumos das histórias. Esta construção foi feita com o auxílio do projetor multimídia, no laboratório de informática, situação essa que permitiu a todos os alunos se empolgarem com a nova criação. Toda esta dinâmica pode ser afirmada nas falas de Miranda et. all, 2011, onde diz que:

"a introdução do uso de TICs na escola traz a possibilidade de que não apenas o contexto no qual os alunos e professores estão inseridos possa ser aproveitado, mas também permite um ambiente de construção e aprendizado mais colaborativo, dinâmico e divertido."

A partir desta divisão, os alunos discutiram os novos possíveis rumos da história, e as versões começaram a ser escritas. Retomamos a discussão sobre o perfil dos personagens a fim de não descaracterizá-los nestas novas versões. Com o texto finalizado, teve início o trabalho de ilustração e novas pesquisas foram necessárias diante do surgimento de dúvidas, como por exemplo: como poderiam ser as casas, palácios e ambientes da região onde se passava a história? Por fim, os alunos, voluntariamente, escolheram quais personagens e ambientes que gostariam de ilustrar. Os desenhos foram feitos à mão e, posteriormente, digitalizados.
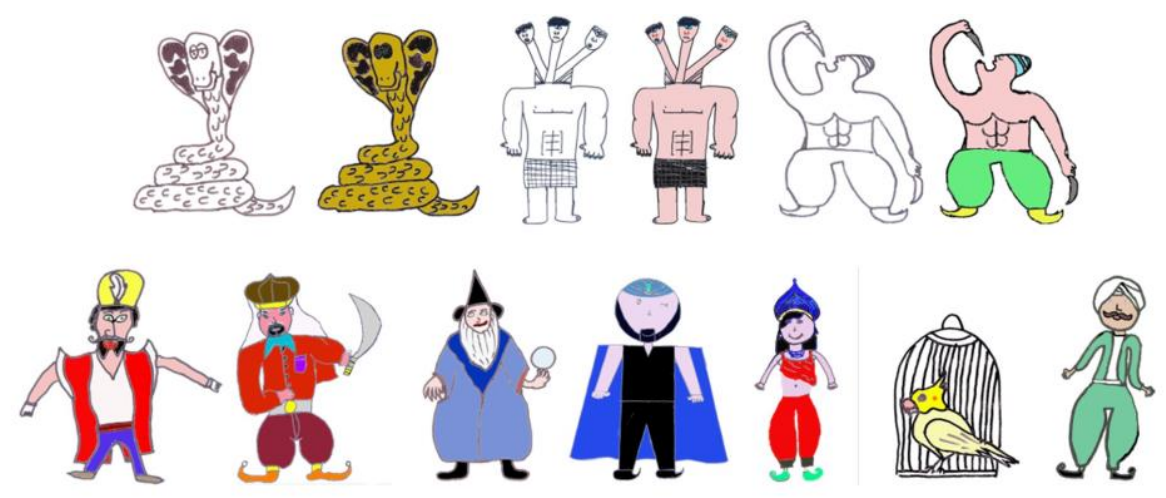

Figura 2 - Personagens desenhados à mão livre, digitalizados e modificados no programa Gimp 2 
Utilizando o programa Gimp, os alunos deixaram o desenho com fundo transparente e coloriram cada detalhe, além de completar as cenas com desenhos criados digitalmente, utilizando também o programa TuxPaint.
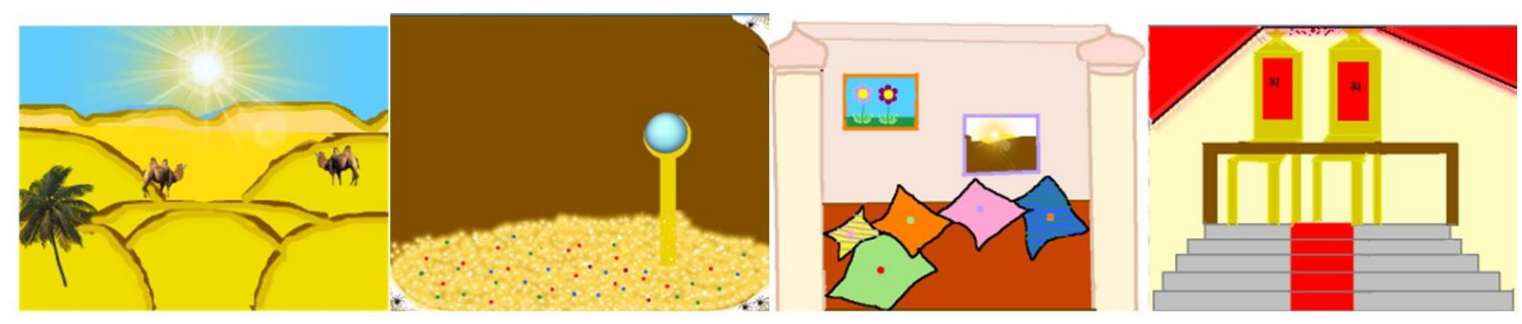

Figura 3 - Paisagens criadas no programa Tux Paint

Os alunos inseriram as imagens no Power Point, com os textos digitados e a navegação foi feita com links, seguindo os caminhos estipulados. Para que pudesse ser publicado sem perder os links, a apresentação foi salva com a extensão .flv, sendo utilizado para isso o programa iSpring. Os livros foram publicados no blog da escola para ficarem acessíveis a toda a comunidade escolar, além de serem também divulgados em nosso ambiente interno para apreciação dos demais estudantes.
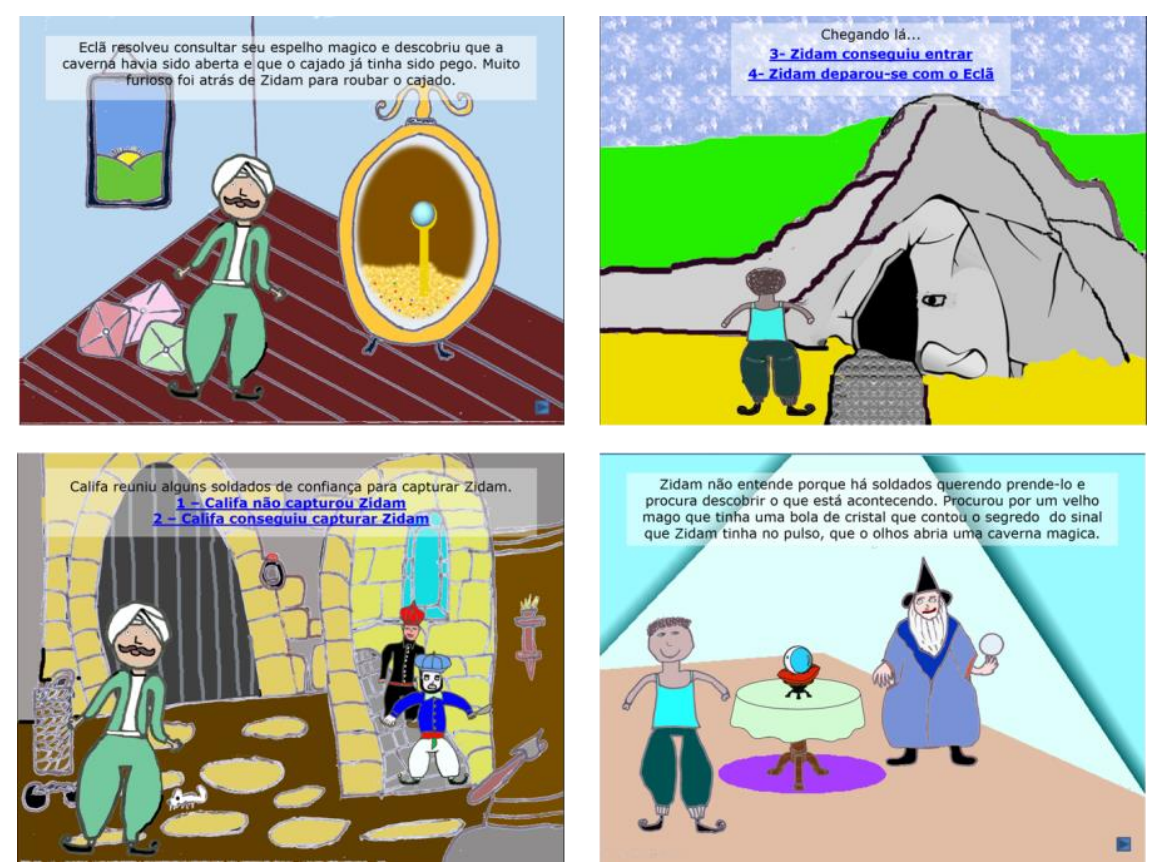

Figura 4 - Exemplos de telas de uma história criada, com os trechos de decisão na segunda e terceira imagem 
Com o trabalho coletivo finalizado, os alunos realizaram a produção de um conto maravilhosos individual. Como continuidade do trabalho, poderão criar, com o auxílio dos laptops educacionais, suas próprias histórias não lineares individualmente.

\section{Resultados e discussões}

O trabalho com esse gênero textual foi muito produtivo, pois trouxe possibilidades de se trabalhar com vários conteúdos de diversas disciplinas. Em História e Geografia foi aprofundado o conhecimento das diferenças e semelhanças entre Oriente e Ocidente. Os alunos se mostraram muito interessados e realizaram várias pesquisas, em que puderam conhecer melhor os usos, costumes e a cultura oriental. O uso dos laptops favoreceu o esclarecimento rápido de dúvidas e a socialização de suas descobertas. Em Arte, conheceram os arabescos e perceberam a diferença entre as formas usadas na arquitetura oriental. Em Ciências, devido ao grande interesse, complementaram o conteúdo estudando sobre o réptil (Naja). Mas o grande avanço foi apresentado em Língua Portuguesa, uma vez que os alunos apresentaram um maior desempenho nas produções textuais.

No início do trabalho os alunos demonstravam pouca criatividade para desenvolver situações em suas histórias, dificuldade que foi sendo vencida, por meio de pesquisas pelas quais iam se repertoriando, desde nomes comuns ou de origem árabe/persa que poderiam ser utilizados em suas produções até a contextualização do por que dos Contos das Mil e Uma Noites, abrindo um leque de possibilidades que fez com que se sentissem mais seguros na criação de suas histórias. O trabalho com esse tipo de gênero textual facilitou esse processo, de modo que os alunos não tivessem receio de criar complicações em seu enredo, pois sempre haveria a possibilidade de inserir um elemento mágico que resolveria a situação. E, por fim, através do exercício de recriação com as novas versões, aprimoraram os seus textos.

A gramática permeou todo trabalho, de forma que a vimos em análises dos textos lidos, nas produções coletivas, individuais e de modo específico, quando usado o corretor ortográfico que possibilitava fazer a autocorreção e sanar dúvidas automaticamente.

O bom resultado obtido na produção textual foi confirmado na reunião de conselho de classes, onde foi constatada uma melhora significativa na produção de textos individuais.

Os recursos tecnológicos enriqueceram todo o trabalho, desde o desenvolvimento das pesquisas, até a finalização, com a digitação do texto, a produção das ilustrações digitais, a criação das opções "interativas" e a publicação do resultado final. A aprendizagem obtida para a produção das imagens possibilitou uma nova comunicação digital além da linguagem escrita, ou seja, a linguagem visual digital, o que favoreceu a apropriação do letramento digital, conforme alertam Velloso e Marinho (2011) para uma concepção de letramento digital que:

"contempla a apropriação de habilidades para que o indivíduo possa ser letrado em diferentes linguagens no contexto digital (...) envolvendo outras linguagens e outras formas que sejam essenciais para comunicar, expressar sentimentos, idéias e experiências nos ambientes virtuais". 


\section{Conclusões e continuidade do trabalho}

Este relato buscou compartilhar uma prática de trabalho que aliou o uso das novas tecnologias ao desenvolvimento da produção de autoria dos alunos, de forma criativa e prazerosa, propiciando uma interação, tanto para o criador, como para o leitor final.

Neste contexto, as NTDICs propiciaram a oportunidade de reinventar um texto que poderia ter sido dado como pronto e envolver os alunos em novos enredos, além de auxiliar no desenvolvimento da linguagem visual, na produção das ilustrações, de modo a dar uma função social para as produções dos alunos, que teriam um leitor real.

Foi relatado o desenvolvimento do trabalho, compartilhando uma prática possível de ser realizada com recursos tecnológicos simples e o uso de programas, em sua maioria, livres.

Ao publicar os trabalhos concluídos ficou evidente como contribuiu para criar uma função social para estas produções, permitindo que, entre outros, os familiares dos alunos, inclusive de localidades distantes, tivessem a oportunidade de conhecer os trabalhos disponibilizados no blog da EMEB. Os dados estatísticos do blog confirmam o acesso de várias localidades e demonstram o poder de socialização da Web.

O trabalho propiciou uma produção diferenciada, a qual vai além do tradicional livro digital com histórias lineares, inserindo novos desafios no texto da narrativa e oferecendo uma nova função para o leitor final.

A continuidade deste trabalho se dará com o aprofundamento individual desta proposta, onde cada aluno construirá sua história não linear com o uso dos netbooks.

Todos os trabalhos serão divulgados na mostra literária que ocorrerá em 30 de novembro de 2013. Os contos podem ser visualizados no blog da EMEB José Cataldi: www.emebjosecataldi.blogspot.com.

\section{Referencias}

MIRANDA, Leonardo Cunha de; HAYASHI, Elaine C. S.; ASSIS, Rosângela de; MARTINS, Maria Cecília; BARANAUSKAS, M. Cecília C. Laptop XO Dentro e Fora da Sala de Aula: Expressão, Diversão e Alfabetização. Publicado nos anais do XXII SBIE - XVII WIE. Disponível em: <http://www.brie.org/pub/index.php/wie/article/view/1976/1735>. Acesso em 10 de agosto de 2013.

PRENSKY, Marc. “Não me atrapalhe, mãe - Eu estou aprendendo!”. São Paulo: Phorte, 2010.

VALENTE, J.A. A Inclusão das Tecnologias Digitais na Educação Infantil. In: Pátio - Educação Infantil, Ano 6, No. 18, p. 29-32, 2008.

VELLOSO, Maria Jacy Maia; MARINHO, Simão Pedro P. Letramento Digital via Web 2.0: uso do site Toondoo em sala de aula. Publicado nos anais do XXII SBIE - XVII WIE, 2011. Disponível em: 
< http://www.br-ie.org/pub/index.php/wie/article/view/1970/1729 >. Acesso em: 10 de agosto de 2013.

\subsection{Referencias utilizadas no desenvolvimento do trabalho em sala de aula}

CANTOM, Katia; MILHAZES, Beatriz. Arte conta Histórias - As mil e uma noites à luz do dia: Sherazade conta Histórias Árabes. São Paulo: Difusão cultural do livro, 1997.

HOLEINONE, Peter; BARALDI, Severino; PERROTI, Denise (tradução). Fábulas de Ouro - Aladim e a Lâmpada Maravilhosa e outras histórias. São Paulo: Paulinas, 2003.

KERVEN, Rosalind; MISTRY, Nilesh. FEIST Hildegard (tradução). Aladim e outros contos de As Mil e uma Noites. São Paulo: Companhia das Letrinhas, 1998.

ROCHA, Ruth; Negro, Maurício. Histórias da Mil e uma Noites. São Paulo: FTD, 2006.

ZIR, Alessandro. As aventuras de Simbad o Marujo. Porto Alegre: Pocket, 2001. 